\title{
The results of a randomized controlled trial of police body-worn video in Australia
}

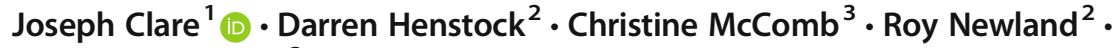 \\ Geoffrey C. Barnes ${ }^{3}$
}

Published online: 9 December 2019

(C) The Author(s) 2019

\begin{abstract}
Objectives We report the results of a randomized controlled trial of police body-worn video (BWV) cameras in an Australian context, with a focus on how cameras influence evidence gathering, court processes/outcomes, and police/public behavior.

Methods The 6-month trial undertaken by the Western Australia Police Force involved a sample of officers $(N=498)$ acting as their own controls with camera use ("treatment") randomly allocated across shifts. A range of parametric and non-parametric tests were conducted to explore the influence of BWV on interview efficiency, rate/timing of guilty pleas, conviction rates, sanction rates, police use-of-force, assaults against police, and citizen complaints against police.

Results The trial generated mixed results in support of this technology within this Australian context. BWV recordings did result in evidence-gathering benefits by producing cost/time efficiencies when taking field interviews. BWV footage had limited impact on court processes/outcomes, with indication that camera evidence encouraged earlier guilty pleas but no corresponding increase in the rate of guilty pleas or convictions. BWV did influence police operational decision-making, with increased sanction rates and use-of-force on treatment days. The extent to which officers engaged with the trial compounded these patterns. There was no evidence that BWV prevents problem behavior, with citizens' complaints increasing on treatment days and no influence of BWV on rates of assaults against police.

Conclusions These findings highlight the need for additional context-specific clarity about why police use BWV cameras. In particular, BWV users should clearly specify the causal mechanisms through which cameras will achieve administrative, evidentiary, operational, and/or problem-prevention goals.
\end{abstract}

Keywords Body-worn video cameras $\cdot$ Randomized controlled trials

Electronic supplementary material The online version of this article (https://doi.org/10.1007/s11292-01909387-w) contains supplementary material, which is available to authorized users.

Joseph Clare

joe.clare@uwa.edu.au

Extended author information available on the last page of the article 


\section{Introduction}

There has been extensive uptake of body-worn video (BWV) cameras by Australian, UK, and US law enforcement agencies in the absence of clear evidence demonstrating camera efficacy (Lum et al. 2019). This paper reports the findings of a 6-month randomized controlled trial of BWV undertaken by the Western Australia Police Force (WAPF) in 2016. The rest of this section briefly explains the link between BWV and the focuses of this trial: evidence gathering, court outcomes, and police/public behavior. ${ }^{1}$

First, with respect to evidence, BWV has produced efficiencies when dealing with complaints against police (Braga et al. 2018) and facilitated evidence collection (Spencer and Cheshire 2018). Second, there is limited and mixed evidence to support a position that BWV is useful for court outcomes. While Spencer and Cheshire (2018) found that BWV positively influenced court outcomes in their study, an analysis of the relationship between BWV footage and judicial outcomes by Yokum et al. (2017) found no such benefits.

Moving on to the influence of BWV on police/public behavior, there is a large body of research across a range of contexts to believe people will behave differently when they think they are being watched (termed the Hawthorne effect: for a systematic review, see McCambridge et al. 2014b). However, there is a range of results across studies, which means it is uncertain the extent to which BWV cameras produce the Hawthorne effect in practice. Two categories of metrics that demonstrate these inconsistencies are operational decisions made by officers wearing BWV and the frequencies of problem behaviors (by police and public) in the presence of BWV.

Focusing on police use-of-force and sanction rates provides insight into the influence of BWV on operational decisions. There are mixed findings regarding the link between BWV and police use-of-force. One body of research does indicate that cameras can reduce use-of-force (e.g., Braga et al. 2018). However, a contrasting set of studies demonstrates no distinguishable impact of BWV on officer use-of-force behavior (e.g., Peterson et al. 2018). BWV camera-wearing officers have also demonstrated an increase in their sanction rates relative to officers without cameras (e.g., Braga et al. 2017). Contrasting these findings, Yokum et al. (2017) concluded that BWV did not influence policing activity. Furthermore, McClure et al. (2017) and Peterson et al. (2018) observed significant reductions in arrests for officers wearing cameras. The varied spectrum of inconsistent outcomes across trial contexts could be due, at least in part, to the interaction between BWV cameras and police discretion (Rowe et al. 2018).

Complaints and assaults against the police are also useful proxies to examine the potential for BWV cameras to prevent problem behavior. There have been some instances where BWV cameras have reduced complaints against police (e.g., Peterson et al. 2018), but this effect is inconsistent, with Ariel et al. (2017) finding no such outcome. There is also a lack of confidence that cameras would protect police from assaults (Ellis et al. 2015; Headley et al. 2017), likely explained by the moderating influence intoxication and familiarity with the criminal justice system would have on "potential" offenders' decision-making (Owens and Finn 2018).

Building on these previous research findings, the trial examined the following hypotheses:

\footnotetext{
${ }^{1}$ For the expanded introduction with additional references, see the online only technical appendix.
} 
- Evidence: BWV cameras and associated digital systems will produce cost and time efficiencies when taking field interviews.

- Court: BWV cameras will increase rates of guilty pleas, result in earlier lodging of guilty pleas, and increase conviction rates.

- Behavior (operational decisions): BWV will increase sanction rates and decrease police use-of-force.

- Behavior (problem prevention): BWV will decrease citizens' complaints against police and assaults against police.

\section{Methods}

\section{Design}

This trial took place in two Western Australian locations: Perth (the state capital) and the regional town of Bunbury (located approximately $2 \mathrm{~h}$ drive to the south of Perth). Perth has a population of over two million people and the Perth policing sub-district encompasses $21 \mathrm{~km}^{2}$ of densely populated residential area, the central business district, and a major entertainment district. In comparison, approximately 45,000 people live in Bunbury, and this regional policing subdistrict covers over $1000 \mathrm{~km}^{2}$ including the town center and a mixture of rural and coastal areas. Selecting these locations enabled WAPF to determine the utility and practicality of implementing BWV in regional and metropolitan settings. Both locations typically generate a wide variety of policing tasks that require officers to have regular contact with the public in diverse settings (ranging from nighttime entertainment precincts through to commercial areas). Furthermore, these areas were likely to generate sufficient incident volume to allow reasonable data gathering during the trial and, from a logistical perspective, both areas could accommodate the necessary training and management requirements for the trial.

During the trial, days were randomly designated as either "treatment" (all participating officers commencing a shift wore and used BWV), or "control" (no officers wore BWV). The treatment/control calendar was prepared at the outset of the trial by a random number generator. Access to this calendar was restricted and, prior to 6 am each day, all officers, supervisors, and district office hierarchy involved in the trial received emails advising the treatment/control status of the day. This design decision maximized the likelihood of "saturation" treatment on treatment days and minimized the likelihood of treatment on control days. For analysis purposes, the treatment/control status for any job, incident, or recording was calculated based on date-time because participating units' shifts did not cover 24-h periods and a late shift commencing one day may have finished at 06:00 $\mathrm{h}$ the following day. Any matter occurring between midnight and 06:00 $\mathrm{h}$ inherited the treatment/control status of the previous day.

On trial days, officers adopted a "limited discretion" approach when attending criminal incidents (officers were directed to record all domestic violence incidents, all incidents involving aggression/violence, all incidents where evidence capture was possible, and all incidents involving use-of-force). Officers retained a high level of discretion as to whether recording was continued and in what other circumstances 
recording was appropriate. During the trial, WAPF officers were operating under the following guidelines ${ }^{2}$ :

- Wear cameras overtly and warn members of the public they were being recorded (using an RCT-specific script), as soon as practicable;

- Ask permission to film in private situations (such as inside homes) and abide by any request to cease filming in such situations; and

- Use mobile telephones linked to BWV to record evidence of incidents and interactions with witnesses/victims of crime in the field.

\section{Sample}

The trial ran from 13 June 2016 to 16 December 2016 and involved 498 officers: $80 \%$ male, average age 36 years, and average 8.3 years' service (Probationary Constables, 5\%; Constables, 28\%; 1 st Class Constables, 25\%; Senior Constables, 23\%; and officers ranked Sergeant and above, 16\%). Due to random variation (treatment/control day allocation) and individual differences in work attendance because of a range of factors (including annual leave, sick leave, alternative duties, court appearances, etc.), officers had varying opportunities to use the cameras during the trial (86 treatment and 101 control days).

\section{Measures}

This evaluation utilized the following operational datasets:

- Incident management system (IMS): criminal and non-criminal incidents, charges laid (including assaults against police ${ }^{3}$ ), sanction rates, other enforcement activities, and information relating to recorded interviews.

- Criminal code infringement notices (CCINs): discretionary, proactive policing action issued for antisocial behavior and/or liquor infringements.

- Computer aided dispatch (CAD): public calls for service and internally generated tasking.

- Use-of-force: reportable use-of-force includes drawing and pointing/discharging a Taser or firearm, or use of baton, handcuffs, police dog/horse, other weapons, or empty hand tactics that result in bodily injury.

- Professional standards complaints: excluding low-level complaints that, in some circumstances, were resolved at police station level without reporting to the Professional Standards Division.

\footnotetext{
${ }^{2}$ For fuller explanation of the recording policy (and other technical issues), see the online only technical appendix.

${ }^{3}$ In Western Australia, assaults against police may involve on- or off-duty officers (provided the accused was aware that they were a police officer) and any level of assault.
} 


\section{Results}

\section{Officer engagement with the trial}

We anticipated there would be variation in the extent to which officers "bought-in" to the initiative (e.g., Spencer and Cheshire 2018). Consequently, this review also examined outcome differences for high- and low-engagement officers, determined as follows. First, the ratio for treatment day CAD attendances per treatment week each officer was rostered was calculated (median $=7.8$ ). Officers whose average CAD attendance exceeded this median had reasonable opportunity to be involved with the trial and technology, if they wanted to. This subset of officers was then ranked on four metrics: (1) domestic violence (DV) attendances that were recorded by BWV (\%, as directed by trial guidelines), (2) video files produced per CAD job (avg.), (3) audio files recorded per CAD job (avg.), and (4) video file recorded (avg. duration). Each officer's equally weighted rank scores were summed (with the lowest ranked score indicative of the greatest engagement with the use of the BWV). The high- and low-engagement officers were the 70 at either end of this ranking distribution. The relative compositions of these two "engagement" groups are displayed in Table 1.

\section{Evidence: Did BWV produce cost/time efficiencies when taking field interviews?}

Officers were directed to conduct an audio record of interview (ARI) using a BWV-linked mobile phone, rather than a "traditional," signed, written (statement) interview wherever possible when interviewing victims or witnesses. Table 2 shows that officers recorded $38 \%$ of their interviews on treatment days and $4 \%$ of interviews on control days. The average duration for these interviews was 14 min (treatment days) and 10 min (control days). By calculating the difference between the average duration for ARIs and statements, the BWV system was estimated to have saved $328 \mathrm{~h}$ on treatment days and $29 \mathrm{~h}$ on control days. The rate of interviews per $1000 \mathrm{CAD}$ jobs was also significantly higher on treatment days. Furthermore, as displayed in Table 3, high-engagement officers were more

Table 1 Engagement analytics and demographics of the high- and low-engagement officers

\begin{tabular}{lll}
\hline Metric & High engagement $(n=70)$ & Low engagement $(n=70)$ \\
\hline CAD attendances per treatment week (median) & 12.5 & 16.1 \\
File recorded per CAD attendance (avg.) & 0.7 & 0.0 \\
Video files per CAD attendance (avg.) & 0.7 & 0.0 \\
DV CAD jobs where a file was recorded (avg. \%) & $55 \%$ & $0 \%$ \\
Sum of contribution - video files & $49 \%$ & $0 \%$ \\
Sum of contribution - video duration & $50 \%$ & $0 \%$ \\
Age & 34.8 & 34.6 \\
Years of service & 5.8 & 7.7 \\
Years at rank & 3.3 & 3.1 \\
\hline
\end{tabular}


Table 2 Relative within-column percentages of interview types, average interview duration (min), and interview rates (per $1000 \mathrm{CAD}$ jobs) for treatment and control day interviews

\begin{tabular}{|c|c|c|c|c|}
\hline \multirow[t]{2}{*}{ Interview type } & \multicolumn{2}{|c|}{$\begin{array}{l}\% \text { Treatment day interviews } \\
(n=1766)\end{array}$} & \multicolumn{2}{|c|}{$\begin{array}{l}\% \text { Control day interviews } \\
(n=1411)\end{array}$} \\
\hline & Column \% & Avg. duration & Column \% & Avg. duration \\
\hline BWV ARIs & $38 \%$ & $14 \mathrm{~min}$ & $4 \%$ & $10 \mathrm{~min}$ \\
\hline Statement & $62 \%$ & $43 \mathrm{~min}$ & $96 \%$ & $43 \mathrm{~min}$ \\
\hline Interviews per $1000 \mathrm{CAD}$ jobs & $27.6^{\mathrm{a}}$ & & $25.1^{\mathrm{a}}$ & \\
\hline
\end{tabular}

Letter pairs (e.g., superscript a,a) indicate statistically significant difference in the rates between the two pairs: $\mathrm{a}-Z=2.65, p<.01$, odds ratio $=1.10(95 \%$ CI low $=1.03$, high $=1.18)$

likely to generate ARIs on treatment days and recorded more interviews on all days relative to low-engagement officers.

\section{Court: Did BWV affect guilty pleas or conviction rates?}

We examined all court records with an offence date within the scope of the trial where the arresting officer's unit was a unit participating in the trial. Because of the way the court data is structured, it was not possible to determine individual officers involved with enough consistency to be able to draw engagement comparisons. Given the time lag between arrest and finalization in court, with a view to maximizing the number of

Table 3 Relative within-column percentages of interview types, average interview duration (min), and interview rates (per $1000 \mathrm{CAD}$ jobs) for treatment and control day interviews by officer engagement

\begin{tabular}{|c|c|c|c|c|c|c|c|c|}
\hline \multirow[t]{3}{*}{ Interview type } & \multicolumn{4}{|c|}{ High engagement } & \multicolumn{4}{|c|}{ Low engagement } \\
\hline & \multicolumn{2}{|c|}{$\begin{array}{l}\% \text { Treatment day } \\
\text { interviews } \\
(n=693)\end{array}$} & \multicolumn{2}{|c|}{$\begin{array}{l}\% \text { Control day } \\
\text { interviews }(n=544)\end{array}$} & \multicolumn{2}{|c|}{$\begin{array}{l}\% \text { Treatment day } \\
\text { interviews }(n=86)\end{array}$} & \multicolumn{2}{|c|}{$\begin{array}{l}\% \text { Control day } \\
\text { interviews }(n=90)\end{array}$} \\
\hline & $\begin{array}{l}\text { Column } \\
\%\end{array}$ & $\begin{array}{l}\text { A v g. } \\
\text { duration }\end{array}$ & $\begin{array}{l}\text { Column } \\
\%\end{array}$ & $\begin{array}{l}\text { A v g . } \\
\text { duration } \\
\text { (min) }\end{array}$ & $\begin{array}{l}\text { Column } \\
\%\end{array}$ & $\begin{array}{l}\text { A v g. } \\
\text { duration }\end{array}$ & $\begin{array}{l}\text { Column } \\
\%\end{array}$ & $\begin{array}{l}\text { A v g . } \\
\text { duration }\end{array}$ \\
\hline BWV ARIs & $53 \% \mathrm{a}^{\mathrm{a}}$ & $13 \mathrm{~min}$ & $5 \%$ & $10 \mathrm{~min}$ & $6 \% \mathrm{a}$ & $21 \mathrm{~min}$ & $0 \%$ & - \\
\hline Statement & $47 \%$ & $43 \mathrm{~min}$ & $95 \%$ & $41 \mathrm{~min}$ & $94 \%$ & $34 \mathrm{~min}$ & $100 \%$ & $44 \mathrm{~min}$ \\
\hline $\begin{array}{l}\text { Interviews per } 1000 \\
\text { CAD jobs }\end{array}$ & $40.0^{\mathrm{b}, \mathrm{c}}$ & & $26.8^{\mathrm{b}, \mathrm{d}}$ & & $8.2^{\mathrm{c}}$ & & $7.7^{\mathrm{d}}$ & \\
\hline
\end{tabular}

Letter pairs (e.g., superscript a,a) indicate statistically significant difference between the two pairs: a- $Z$-test for difference in proportions, $Z=22.42, p<.001$, odds ratio $=18.03(95 \% \mathrm{CI}$ low $=7.22$, high $=45.03)$; b- $Z$ test for the rate ratios, $Z=6.97, p<.0001$, odds ratio $=1.51(95 \% \mathrm{CI}$ low $=1.35$, high $=1.69)$; c- $-Z$-test for the rate ratios, $Z=19.47, p<.0001$, odds ratio $=5.02(95 \% \mathrm{CI}$ low $=4.01$, high $=6.29)$; and d- $Z$-test for the rate ratios, $Z=21.31, p<.0001$, odds ratio $=3.54(95 \%$ CI low $=2.83$, high $=4.43)$ 
events that had been finalized, this data extract was undertaken in April 2017 (4 months after the trial had been concluded). In total, 5006 of 7803 offences (64\% of the eligible offences) had entered a guilty plea at this time.

Examination of guilty plea rates found no significant difference between cases from treatment (65.3 guilty pleas per 100 offences) and control (63.9 per 100 offences) days ( $Z$-test for the rate ratios, $Z=0.75, p>.22$ ). With the intent of capturing incidents where the BWV footage may have been used in prosecution and/or disclosed to the offender or their legal team, a sub-set of cases $(n=210)$ with BWV-relevant phrases entered into the Statement of Material Facts (SOMF) was identified. Analysis of this sub-set also demonstrated a non-significant difference between treatment (60.5 guilty pleas per 100 offences) and control (63.9 per 100 offences, $Z$-test for the rate ratios, $Z=-0.60, p>$ .27). There was also no significant difference between the total treatment and control day conviction rates (76.3 per 100 offences in both instances, $Z=0.02, p>.49$ ), nor for the subset of cases where BWV was listed in the SOMF (81.4 per 100 offences, $Z=-$ $0.82, p>.20)$.

There was support for the expectation that BWV encourages earlier guilty pleas. Of the 5006 offences for which a guilty plea had been entered, $55.5 \%$ were entered on the first or second appearance and $89.6 \%$ had been entered by the sixth appearance, by which time there were significantly more treatment day offences finalized $(91.0 \%$ vs. $87.7 \%$ of control cases, $Z=3.63, p<.001$, odds ratio $=1.41(95 \% \mathrm{CI}$ low $=1.17$, high $=1.69)$ ). There was indication that the timing of pleas was influenced for the sub-set of matters where the existence of BWV footage was recorded in the SOMF (47.2\% of the 127 matters resolved by plea at the first appearance vs. $35.2 \%$ of first appearances for control offences, $Z=2.65, p<.005$, odds ratio $=1.65(95 \% \mathrm{CI}$ low $=1.15$, high $=$ 2.36)).

\section{Behavior (operational decisions): Did BWV affect sanction rates and use-of-force?}

To test whether BWV increased sanction rates on treatment days, we examined CCINs, criminal charges, police-issued restraining order ${ }^{4}$ issue, and move-on notices ${ }^{5}$ (see Table 4). The rates of criminal charges and move-on notices issued were significantly greater on treatment days. Officer engagement also influenced sanction rates (Table 5), with high-engagement officers generally demonstrating greater sanction rates on treatment days relative to their own rates on control days and low-engagement officers on all days.

High-end use-of-force events in the WAPF are very rare. Despite this, for the 106 incidents recorded during the trial period, the use-of-force rate was higher on treatment days (1.0 per $1000 \mathrm{CAD}$ jobs) relative to control days $(0.7$ per $1000 \mathrm{CAD}$ jobs, $Z=-$ $2.04, p<.03$, odds ratio $=1.51(95 \% \mathrm{CI}$ low $=1.02$, high $=2.24)$ ).

\footnotetext{
${ }^{4}$ An order placing conditions on a bound party in order to provide immediate but temporary (up to $72 \mathrm{~h}$ ) protection to a person affected by "suspected" incidents of family violence.

${ }^{5}$ A formal notice requiring adults/juveniles to leave a nominated public place in order to prevent a likely breach of the peace or commission of other offences.
} 
Table 4 Sanction rates (per 1000 CAD jobs) for treatment and control days

\begin{tabular}{lll}
\hline Sanction type & $\begin{array}{l}\text { Treatment day } \\
\text { (rate per 1000 CAD jobs) }\end{array}$ & $\begin{array}{l}\text { Control date } \\
\text { (rate per 1000 CAD jobs) }\end{array}$ \\
\hline CCINs & 13.6 & 13.5 \\
Criminal charges & $139.2^{\mathrm{a}}$ & $125.5^{\mathrm{a}}$ \\
Restraining orders & 4.4 & $4.5^{5}$ \\
Move-on notices & $42.4^{\mathrm{b}}$ & $38.2^{\mathrm{b}}$ \\
\hline
\end{tabular}

Letter pairs (e.g., superscript a,a) indicate statistically significant difference in the rates between the two pairs: $\mathrm{a}-Z=6.53, p<.0001$, odds ratio $=1.13(95 \%$ CI low $=1.09$, high $=1.17) ; \mathrm{b}-Z=3.64, p<.0001$, odds ratio $=1.12(95 \%$ CI low $=1.05$, high $=1.18)$

\section{Behavior (problem prevention): Did BWV affect complaints and assaults against police?}

Citizen complaints and assaults against WAPF officers are also very infrequent events. During the trial, 44 incidents $(0.04 \%$ of all incidents during the trial) generated 67 complaints. Overall, complaints were more frequent on treatment days $(0.7$ per 1000 CAD jobs) relative to control days ( 0.4 per $1000 \mathrm{CAD}$ jobs, $Z=2.25, p<.02$, odds ratio $=1.80(95 \% \mathrm{CI}$ low $=1.08$, high $=2.99))$. For the 95 assaults on police that occurred during the trial period, there was no significant difference in the rate on treatment days $(0.8$ per $1000 \mathrm{CAD}$ jobs $)$ and control days $(0.7$ per $1000 \mathrm{CAD}$ jobs, $Z=$ $0.50, p>.30)$.

Table 5 Sanction rates (per 1000 CAD jobs) for treatment and control days by officer engagement

\begin{tabular}{|c|c|c|c|c|}
\hline \multirow[t]{2}{*}{ Sanction type } & \multicolumn{2}{|l|}{ High engagement } & \multicolumn{2}{|l|}{ Low engagement } \\
\hline & $\begin{array}{l}\text { Treatment day (rate } \\
\text { per } 1000 \mathrm{CAD} \text { jobs) }\end{array}$ & $\begin{array}{l}\text { Control day (rate per } \\
1000 \text { CAD jobs) }\end{array}$ & $\begin{array}{l}\text { Treatment day (rate } \\
\text { per } 1000 \text { CAD jobs) }\end{array}$ & $\begin{array}{l}\text { Control day (rate per } \\
1000 \text { CAD jobs) }\end{array}$ \\
\hline CCINs & 5.4 & 4.2 & $5.4^{\mathrm{a}}$ & $3.3^{\mathrm{a}}$ \\
\hline $\begin{array}{l}\text { Criminal } \\
\text { charges }\end{array}$ & $104.5^{\mathrm{b}, \mathrm{c}}$ & $64.3^{\mathrm{b}, \mathrm{e}}$ & $55.5^{\mathrm{c}, \mathrm{d}}$ & $32.7^{\mathrm{d}, \mathrm{e}}$ \\
\hline $\begin{array}{l}\text { Restraining } \\
\text { orders }\end{array}$ & $9.3^{\mathrm{f}, \mathrm{g}}$ & $6.8^{\mathrm{f}, \mathrm{h}}$ & $1.5^{\mathrm{g}}$ & $1.3^{\mathrm{h}}$ \\
\hline $\begin{array}{l}\text { Move-on } \\
\text { notices }\end{array}$ & $18.5^{\mathrm{i}, \mathrm{j}}$ & $11.7^{\mathrm{i}, \mathrm{k}}$ & $1.7^{\mathrm{j}}$ & $1.7^{\mathrm{k}}$ \\
\hline
\end{tabular}

Letter pairs (e.g., superscript a,a) indicates statistically significant difference in the rates between the two pairs: $\mathrm{a}-Z=2.26, p<.02$, odds ratio $=1.60(95 \% \mathrm{CI}$ low $=1.07$, high $=2.42) ; \mathrm{b}-Z=13.37, p<.0001$, odds ratio $=1.70(95 \% \mathrm{CI}$ low $=1.58$, high $=1.83) ; \mathrm{c}-Z=13.27, p<.0001$, odds ratio $=1.99(95 \% \mathrm{CI}$ low $=1.80$, high $=2.19) ; \mathrm{d}-Z=8.03, p<.0001$, odds ratio $=1.74(95 \%$ CI low $=1.52$, high $=1.98) ; \mathrm{e}-Z=11.62, p<.0001$, odds ratio $=2.03(95 \% \mathrm{CI}$ low $=1.81$, high $=2.28) ; \mathrm{f}-Z=2.80, p<.01$, odds ratio $=1.39(95 \% \mathrm{CI}$ low $=$ 1.10 , high $=1.74) ; \mathrm{g}-Z=6.90, p<.0001$, odds ratio $=6.15(95 \% \mathrm{CI}$ low $=3.68$, high $=10.29) ; \mathrm{h}-Z=6.10$, $p<.0001$, odds ratio $=5.28(95 \% \mathrm{CI}$ low $=3.10$, high $=9.00) ; \mathrm{i}-Z=5.30, p<.0001$, odds ratio $=1.58(95 \%$ CI low $=1.34$, high $=1.88) ; \mathrm{j}-Z=9.79, p<.0001$, odds ratio $=10.91(95 \% \mathrm{CI}$ low $=6.78$, high $=17.54)$; and $\mathrm{k}-Z=8.26, p<.0001$, odds ratio $=6.91(95 \% \mathrm{CI}$ low $=4.38$, high $=10.91)$ 


\section{Discussion}

There were indications that BWV recordings have an evidentiary value through cost/time efficiencies when taking field interviews. However, the ARI capability interacted with officer engagement to influence the likelihood of an interview being undertaken and the likelihood of the interview being captured using the cameras/phones. Further research should seek to uncover the drivers for these patterns and also examine how the potential time savings from recorded interviews hold-up downstream in the investigative process.

From the court perspective, there was limited indication that BWV evidence encouraged earlier guilty pleas, but no evidence that the rate of guilty pleas or convictions increased. Anecdotal evidence from officers involved in the trial may partially explain this, with a large majority indicating at the time of analysis very few of the incidents they had attended when using BWV had appeared in court, and when cases had appeared in court there was a feeling that the BWV footage was not readily accepted (Clare et al. 2019). Furthermore, we note that this study was limited because not all of the cases were finalized at the time of the analysis. This issue warrants further research to allow all cases to be finalized, examine issues such as offence types involved, and explore the extent to which the existence and nature of BWV was disclosed/accepted during trial.

Looking at behavioral change and operational decisions, there was evidence that BWV increased sanction rates and this pattern was moderated by officer engagement. When considering police use-of-force and the potential preventive value of BWV, expectations based on the Hawthorne effect were not supported. Both police use-offorce and citizens' complaints increased on treatment days and there was no influence of BWV on rates of assaults against police. The potential influence of context-specific "floor effects" on these results should be considered, as it was difficult for already-lowfrequency events to decline as the result of an intervention, and small-number variation makes it difficult to reliably interpret the patterns surrounding low-frequency events.

To conclude, the authors want to propose some questions for consideration by other police agencies interested in implementing this technology. First, what is the purpose of BWV in a police setting? For example, are they intended to improve evidence gathering and provide efficiencies, improve the public's sense of police legitimacy, or change public/police behavior (and if so, when, where, and how)? Recent works by Piza (2018) and Malm (2019) critique current approaches to using BWV, highlighting the inconsistent, unclear causal mechanism(s) through which cameras are intended to simultaneously address multiple, competing goals. It is likely that future BWV camera interventions would benefit from additional pre-implementation focus on determining the context-specific mechanisms by which BWV is a part of the solution to existing problems. Additional clarity around purposes for the cameras will help determine how to utilize this technology and appropriately measure its impact.

Next, how do you minimize the dilution of impact caused by disengaged officers? Unfortunately, randomization does not guard against disengaged participants (McCambridge et al. 2014a), so understanding more about why some people engage with the cameras is crucial to maximizing and evaluating the efficacy of BWV. The significant impacts of engagement level identified in this review suggest that police forces would benefit from identifying and monitoring drivers of high and low engagement. 
Finally, prior to implementing BWV, police agencies should consider the (publically funded) cost-benefit ratio of deployment (see Piza (2018), for a discussion of these issues). This is not to argue that cameras cannot have a cost-saving effect (e.g., Braga et al. (2018) discuss cost savings in terms of reduction in citizen complaints resulting from camera use), nor that cost savings should be a sole/primary driver of BWV deployment, but instead to ensure police departments consider factors such as starting rates for complaints, mechanism-specific, targeted use of cameras, and develop realistic expectations of their likely benefits/impact before commencing wholescale rollout.

Acknowledgments The authors would like to thank all of the frontline officers who participated in the trial, along with their supervisors and district management. We would also like to thank everyone involved with providing the necessary individual data sets for the analysis.

Funding information The external evaluation of this police-led initiative was funded by the Western Australian Police.

\section{Compliance with ethical standards}

Conflict of interest Joseph Clare acted as an external University consultant when undertaking this research.

Open Access This article is distributed under the terms of the Creative Commons Attribution 4.0 International License (http://creativecommons.org/licenses/by/4.0/), which permits unrestricted use, distribution, and reproduction in any medium, provided you give appropriate credit to the original author(s) and the source, provide a link to the Creative Commons license, and indicate if changes were made.

\section{References}

Ariel, B., Sutherland, A., Henstock, D., Young, J., \& Sosinski, G. (2017). The deterrence spectrum: explaining why police body-worn cameras 'work' or 'backfire' in aggressive police-public encounters. Policing: A Journal of Policy and Practice, 12(1), 6-26.

Braga, A., Coldren, J. R., Sousa, W., Rodriguez, D., \& Alper, O. (2017). The benefits of body-worn cameras: new findings from a randomized controlled trial at the Las Vegas Metropolitan Police Department. Retrieved from https:/www.cna.org/cna_files/pdf/IRM-2017-U-016112-Final.pdf. Accessed 31 May 2018.

Braga, A., Sousa, W., Coldren, J. R., \& Rodriguez, D. (2018). The effects of body-worn cameras on police activity and police-citizen encounters: a randomized controlled trial. Journal of Criminal Law and Criminology, 108(3), 511-538.

Clare, J., Henstock, D., McComb, C., Newland, R., Barnes, G. C., Lee, M., \& Taylor, E. (2019). Police, public, and arrestee perceptions of body-worn video: a single jurisdictional multiple-perspective analysis. Criminal Justice Review. https://doi.org/10.1177/0734016819846236.

Ellis, T., Jenkins, C., \& Smith, P. (2015). Body-worn video: evaluation of the introduction of personal issue body worn video cameras (Operation Hyperion) on the Isle of Wight - final report to Hampshire Constabulary. Retrieved from https:/www.researchgate.net/publication/273439350_Evaluation_of the_ Introduction_of_Personal_Issue_Body_Worn_Video_Cameras_Operation_Hyperion_on_the_Isle_of_Wight_Final_Report_to_Hampshire_Police_2015. Accessed 19 Apr 2018.

Headley, A. M., Guerette, R. T., \& Shariati, A. (2017). A field experiment of the impact of body-worn cameras (BWCs) on police officer behavior and perceptions. Journal of Criminal Justice, 53, 102-109. https://doi. org/10.1016/j.jcrimjus.2017.10.003.

Lum, C., Stoltz, M., Koper, C., \& Scherer, A. (2019). Research on body-worn cameras: what we know, what we need to know. Criminology \& Public Policy, 18(1), 1-26. https://doi.org/10.1111/1745-9133.12412. 
Malm, A. (2019). Promise of police body-worn cameras. Criminology \& Public Policy, 18(1), 119-130. https://doi.org/10.1111/1745-9133.12420.

McCambridge, J., Kypri, K., \& Elbourne, D. R. (2014a). In randomization we trust? There are overlooked problems in experimenting with people in behavioral intervention trials. Journal of Clinical Epidemiology, 67(3), 247-253. https://doi.org/10.1016/j.jclinepi.2013.09.004.

McCambridge, J., Witton, J., \& Elbourne, D. R. (2014b). Systematic review of the Hawthorne effect: new concepts are needed to study research participation effects. Journal of Clinical Epidemiology, 67(3), 267277. https://doi.org/10.1016/j.jclinepi.2013.08.015.

McClure, D., La Vigne, N., Lynch, M., Golian, L., Lawrence, D., \& Malm, A. (2017). How body cameras affect community members' perceptions of police: results from a randomized controlled trial of one agency's pilot. Retrieved from Washington DC, The Urban Institute, Justice Police Centre

Owens, C., \& Finn, W. (2018). Body-worn video through the lens of a cluster randomized controlled trial in London: implications for future research. Policing: A Journal of Policy and Practice, 12(1), 77-82. https://doi.org/10.1093/police/pax014.

Peterson, B. E., Yu, L., La Vigne, N., \& Lawrence, D. (2018). The Milwaukee Police Department's body-worn camera program: evaluation findings and key takeaways. Retrieved from https://www.urban. org/research/publication/milwaukee-police-departments-body-worn-camera-program\#.Wv13k64DpbA. twitter. Accessed 21 May 2018.

Piza, E. L. (2018). The history, policy implications, and knowledge gaps of the CCTV literature: insights for the development of body-worn video camera research. International Criminal Justice Review. https://oi. org/10.1177/1057567718759583.

Rowe, M., Pearson, G., \& Turner, E. (2018). Body-worn cameras and the Law of Unintended Consequences: some questions arising from emergent practices. Policing: A Journal of Policy and Practice, 12(1), 8390. https://doi.org/10.1093/police/pax011.

Spencer, D., \& Cheshire, R. (2018). Ten years of body worn video in Northamptonshire Police. Policing: A Journal of Policy and Practice, 12(1).

Yokum, D., Ravishankar, A., \& Coppock, A. (2017). Evaluating the effects of police body-worn cameras: a randomized controlled trial. Retrieved from http://bwc.thelab.dc.gov/TheLabDC_MPD_BWC_Working _ Paper_10.20.17.pdf. Accessed 28 May 2018.

Publisher's note Springer Nature remains neutral with regard to jurisdictional claims in published maps and institutional affiliations.

Joseph Clare is a senior lecturer in Criminology within the School of Law at the University of Western Australia

Darren Henstock is an acting inspector with the Western Australian Police Force, operating as the Program Manager - Digital Policing Program

Christine McComb is a data analytics and assessment officer with the Western Australian Police Force, working within the Office of Applied Criminology

Roy Newland is a senior sergeant with the Western Australian Police Force, operating as the Project Lead Body Worn Camera Capability and CoordinationPortfolio

Geoffrey C. Barnes is the director of Criminology, Capability and Coordination Portfolio, Western Australian Police Force 


\section{Affiliations}

\section{Joseph Clare ${ }^{1}$ - Darren Henstock ${ }^{2}$ - Christine $\mathrm{McComb}^{3} \cdot$ Roy Newland ${ }^{2}$.} Geoffrey C. Barnes ${ }^{3}$

1 The University of Western Australia, M253, 35 Stirling Highway, Perth, WA 6009, Australia

2 Digital Policing Program, Capability and Coordination Portfolio, Western Australian Police, 11th Floor, Westralia Square, 141 St. Georges Terrace, Perth, WA 6000, Australia

3 Standards, Practices and Evaluation Division, Western Australian Police, 2 Adelaide Terrace, East Perth, WA 6004, Australia 